Document downloaded from:

http://hdl.handle.net/10251/40396

This paper must be cited as:

Serrano Cruz, JR.; Arnau Martínez, FJ.; Piqueras Cabrera, P.; Garcia Afonso, O. (2013). Packed bed of spherical particles approach for pressure drop prediction in wall-flow DPFs (diesel particulate filters) under soot loading conditions. Energy. 58:644-654. doi:10.1016/j.energy.2013.05.051.

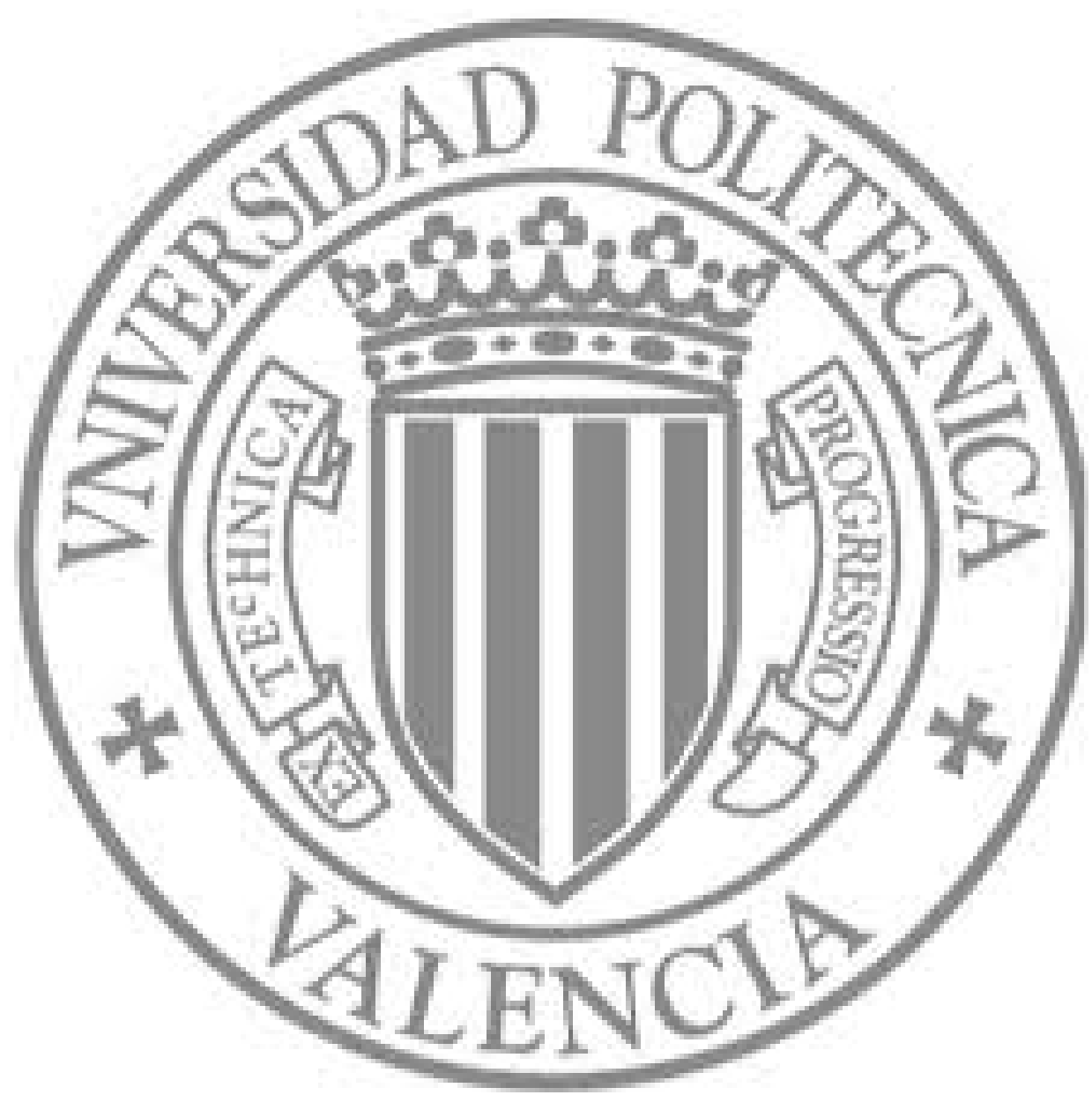

The final publication is available at

http://dx.doi.org/10.1016/j.energy.2013.05.051

Copyright Elsevier 


\title{
Packed bed of spherical particles approach for pressure drop prediction in wall-flow DPFs under soot loading conditions
}

\author{
José Ramón Serrano, Francisco José Arnau, Pedro Piqueras *, Óscar García-Afonso \\ Universitat Politècnica de València, CMT-Motores Térmicos, Camino de Vera s/n, 46022 Valencia, Spain.
}

\begin{abstract}
The soot loading process in wall-flow DPFs affects the substrate structure depending on the filtration regime and produces the increase of pressure drop. Deep bed filtration regime produces the decrease of the porous wall permeability because of the soot particulates deposition inside it. Additionally, a layer of soot particulates grows on the porous wall surface when it becomes saturated. As soot loading increases, the pressure drop across the DPF depends on the porous wall and particulate layer permeabilities, which are in turn function of the substrate and soot properties. The need to consider the DPF pressure drop influence on engine performance analysis or DPF regeneration processes requires the use of low-computational effort models describing the structure of the soot deposition and its effect on permeability. This paper presents a model to describe the micro-scale of the porous wall and the particulate layer structure assuming them as packed beds of spherical particles. To assess the model's capability, it is applied to predict the DPF pressure drop under different experimental conditions in soot loading, mass flow and gas temperature.
\end{abstract}

Keywords: Diesel engines, aftertreatment, diesel particulate filter, soot loading, micro-scale properties

\section{Introduction}

Diesel engines are gaining in growth acceptance with respect to other alternatives, as gasoline engines, mainly because of its higher efficiency leading to lower $\mathrm{CO}_{2}$ emissions, as discussed by Sullivan et al. [1] as general trend in powered vehicles and Zervas et al. [2] from the perspective of global emissions in the case of Greece. Research activities in different but synergistic areas have contributed to strengthen this advantage. Analysis of the injection [3] and combustion processes [4], use of fuel blends and the understanding of its influence on the combustion process [5] and the overall engine efficiency and emissions [6], study of turbocharger architectures, both two-stage turbocharging [7] and supercharger solutions [8], developments in exhaust gas recirculation [9] or advances in control techniques [10] are examples of the activities on which manufacturers and researchers are focusing the resources to improve the Diesel engine performance.

${ }^{*}$ P. Piqueras. CMT-Motores Térmicos, Universitat Politècnica de València, Camino de Vera s/n, 46022 Valencia, Spain. Phone: +34 963877650 Fax: +34 963877659 e-mail: pedpicab@ mot.upv.es 
Although all these improvements also contribute to the reduction of exhaust emissions, the stringent pollutant regulations impose the need to resort to aftertreatment systems for $\mathrm{CO}, \mathrm{HC}$, soot and NOx control. In the case of soot emission, diesel particulate filters (DPF), and mainly wall-flow DPFs, were identified several decades ago as the most effective system to reduce it although they were not widely implanted until the beginning of the present century [11].

A wall-flow DPF consists of a monolithic structure with a bundle of axial parallel channels, which are of small and, typically, square cross section. Channels are alternatively plugged at each end, so that the gas in open channels at inlet monolith cross section (inlet channels) is forced to flow across the porous wall of the ceramic substrate. The flow goes into the outlet channels and finally leaves the monolith. Particles are removed from the exhaust gas when they flow through the porous wall being the performance of a wall-flow DPF based on high filtration efficiency. The filtration process involves the loading of the porous wall. It is finally saturated of soot mass, so that particles begin to be deposited on the walls forming a particulate layer. This process means the time dependant increase of the DPF pressure drop and hence the increase of specific fuel consumption due to the increasing engine back-pressure. Eventually, if the engine operating conditions and the DPF catalytic characteristics do not promote a passive regeneration event, active strategies, which are usually based on fuel injection, are carried out. Their application avoids an excessive DPF soot loading that may lead to inlet channels clogging or uncontrollable regenerations.

Wall-flow DPF modelling is based on the combination of a set of specific sub-models devoted to flow transport and accounting for pressure drop, heat transfer, filtration and regeneration [12]. Usually, DPF models are included as a part of gas dynamics codes for whole engine modelling. In this context, studies focused on engine performance where aftertreatment simulation is key, like the case of pre-turbo aftertreatment architectures [13] or optimised aftertreatment concepts [14], the modelling of the wall-flow DPF is limiting; DPF is setting the engine back-pressure but, as stated by Masoudi [15], its pressure drop is strongly dependent on micro-scale properties of the porous media, i.e. the bare porous wall, variations in its properties due to the penetration of soot deposits and the particulate layer [16]. The same problem arises in studies dedicated to the behaviour of the DPF during regeneration, in which DPF properties related to soot loading conditions must be hypothesised to set a basis from which focus the study on the chemical aspects [17].

Although the specific micro-scale properties of the particulate layer and the loaded porous wall depend on previous history of engine operation, on fuel properties and on engine and DPF characteristics, a description of the involved parameters can be performed. With this scope, a model for pressure drop prediction in loaded wall-flow DPFs is presented and discussed in this paper. The model is based on a packed-bed of spherical particles approach, both for the porous wall and the particulate layer, whose purpose is the prediction of the permeability in the porous substrates. Assuming simple hypothesis to overcome the constraints coming from the lack of specific information regarding the loading process, the micro-scale properties of the porous media are described both during deep bed and cake filtration regimes. Dynamics of soot mass deposition into the porous wall is described based on soot packing density inside the porous wall and a shape factor dependent on soot penetration and loading. During the cake filtration regime the porosity and the collector diameter of the particulate layer control the DPF pressure drop. Representative values for 
all these parameters and its relation with the slip flow correction in the porous wall and the particulate are discussed and compared with available literature data. This task is performed by means of the modelling of several DPFs, which differ in micro-and macro-geometry. In order to assess the model in a wide representative range of operating conditions, the tested conditions of every DPF cover the influence of soot mass loading level, mass flow and gas temperature on the pressure drop.

\section{Flow path modelling}

The proposed model for pressure drop prediction in loaded DPFs is part of a fluid dynamic model for onedimensional flow in wall-flow diesel particulate filters [12]. It is in turn included into a gas dynamic code socalled OpenWAM ${ }^{\mathrm{TM}}[18,19]$. The wall-flow DPF model solves the governing equations for non-homentropic onedimensional unsteady compressible flow along a pair of inlet and outlet channels:

- Mass conservation

$$
\frac{\partial\left(\rho_{j} F_{j}\right)}{\partial t}+\frac{\partial\left(\rho_{j} u_{j} F_{j}\right)}{\partial x}=(-1)^{j} 4\left(\alpha-2 w_{p l} j\right) \rho_{j} u_{w_{j}}
$$

- Momentum conservation

$$
\frac{\partial\left(\rho_{j} u_{j} F_{j}\right)}{\partial t}+\frac{\partial\left(\rho_{j} u_{j}^{2} F_{j}+p_{j} F_{j}\right)}{\partial x}-p_{j} \frac{d F_{j}}{d x}=-F_{w} \mu_{j} u_{j}
$$

- Energy conservation

$$
\begin{aligned}
& \frac{\partial\left(e_{0 j} \rho_{j} F_{j}\right)}{\partial t}+\frac{\partial\left(h_{0 j} \rho_{j} u_{j} F_{j}\right)}{\partial x}= \\
& q_{j} \rho_{j} F_{j}+(-1)^{j} 4\left(\alpha-2 w_{p l} j\right) h_{0 w} \rho_{j} u_{w_{j}}
\end{aligned}
$$

Subscript $j$ in Eqs. (1)-(3) identifies the type of monolith channel. It takes value 0 for the solution of the outlet channels and value 1 in the case of the inlet channels.

The model solves the governing equations in a single pair of inlet and outlet channels. Nevertheless, it is possible to discretise the monolith radially in concentric channel beams in order to include temperature and flow mal-distribution in the radial direction [20]. In this case, one pair of inlet and outlet channels are solved per channel beam, so that all the pairs of channels in the same beam have the same profile of flow properties in the axial direction. 


\subsection{Pressure drop across the porous media}

The conservation equation system is closed in every axial node by the state equation for an ideal gas and the equation defining the pressure drop across the porous medium. This allows obtaining the filtration velocity. In a loaded wall-flow DPF the pressure drop is governed by the Darcy's law applied to the porous substrate and the particulate layer according to Eq. 4 [12]

$$
\Delta p=\frac{\mu_{o} u_{w_{o}} w_{w}}{k_{w}}+\frac{\mu_{i} u_{w_{i}}\left(\alpha-2 w_{p l}\right)}{2 k_{p l}} \ln \left(\frac{\alpha}{\alpha-2 w_{p l}}\right),
$$

where $u_{w_{i}}$ and $u_{w_{o}}$ are the filtration velocity in the inlet and outlet channels respectively. Assuming quasi-steady flow in the porous medium, these velocities are related by the continuity equation:

$$
u_{w_{i}} \rho_{i}\left(\alpha-2 w_{p l}\right)=u_{w_{o}} \rho_{o} \alpha
$$

The inertial contribution to the pressure drop in porous media given by the Forchheimer's term has been not included in Eq. 4. It affects in a lesser extent in wall-flow DPFs because of the low flow velocity along the monolith channels [12].

The coupled solution of the governing equations in the inlet and outlet channels by means of shock capturing methods, which solve internal nodes [21] and boundary conditions [22], provides the values of the gas pressure at every axial position at time $t$. Therefore, the pressure drop and then the filtration velocity can be determined at every axial node of the channels. The obtained values are next applied to the solution of governing equations at time $t+\Delta t$.

As shown in Eq. 4, the filtration velocity is dependent on the gas properties, the monolith cellular geometry and the permeability of the porous media, distinguishing between porous wall $\left(k_{w}\right)$ and particulate layer $\left(k_{p l}\right)$. Hence, the importance of a proper determination of the permeability of every porous medium.

\section{Porous wall permeability}

The permeability of the porous substrate is dependent on the porous structure, i.e. porosity and mean pore diameter, the slip-flow effect and the soot loading. Considering that the structure of the porous wall is well represented by a packed bed of spherical particles [23], the permeability of a clean DPF can be related to the structure of the porous wall and the flow properties according to Eq. 6 [24]

$$
k_{w_{0}}=f\left(\varepsilon_{w_{0}}\right) d_{c, w_{0}}^{2} S C F_{w_{0}},
$$

where $\varepsilon_{w_{0}}$ is the porosity of the clean substrate and $f\left(\varepsilon_{w_{0}}\right)$ is a function of the Kuwabara's hydrodynamic factor [25]:

$$
f\left(\varepsilon_{w_{0}}\right)=\frac{0.02\left(2-\frac{9}{5}\left(1-\varepsilon_{w_{0}}\right)^{\frac{1}{3}}-\varepsilon_{w_{0}}-\frac{1}{5}\left(1-\varepsilon_{w_{0}}\right)^{2}\right)}{1-\varepsilon_{w_{0}}}
$$


The mean grain diameter of the substrate is represented by $d_{c, w_{0}}$, which is referred as the mean diameter of the collector unit in clean conditions. In a packed bed of spherical particles the mean pore diameter is a function of $\varepsilon$ and $d_{c}$, what for the case of a clean DPF substrate is written as:

$$
d_{p, w_{0}}=\frac{2}{3} \frac{\varepsilon_{w_{0}}}{1-\varepsilon_{w_{0}}} d_{c, w_{0}}
$$

The Stokes-Cunningham factor (SCF) accounts for the continuum to slip fluid dynamics. It is dependent on the Knudsen number, which is defined as function of the gas mean free path and the mean pore diameter. In a clean DPF the SCF is obtained according to Eq. 9:

$$
\begin{gathered}
S C F_{w_{0}}=1+K n_{w_{0}}\left(1.257+0.4 e^{\frac{-1.1}{K n_{w_{0}}}}\right) \\
K n_{w_{0}}=\frac{2 \lambda}{d_{p, w_{0}}}
\end{gathered}
$$

\subsection{Effect of soot loading on porous wall structure}

When the DPF porous wall is loaded, soot particulates arranges around the collector unit till the blocking of the cell unit. The cell unit is an sphere that has the same porosity than the porous wall, so that its diameter is given by:

$$
d_{c e l l, w}=\frac{d_{c, w_{0}}}{\left(1-\varepsilon_{w_{0}}\right)^{\frac{1}{3}}}
$$

The soot particulates are usually assumed to be uniformly deposited around the collector unit, so that its diameter growths according to Eq. 12

$$
d_{c, w}=2\left(\frac{d_{c, w_{0}}^{3}}{8}+\frac{3 m_{s_{c e l l}}}{4 \pi \rho_{s, w}}\right)^{\frac{1}{3}},
$$

where $m_{s_{c e l l}}$ is the mass of soot particulates inside the cell unit and $\rho_{s, w}$ is the packing density of the particulates inside the porous wall. It is important to note that $\rho_{s, w}$ is an apparent density that sets the density of the region used by the soot particulates in order to get a perfect spherical growth of the collector unit. It is a mathematically estimated parameter to set the hydrodynamic diameter of the collector unit as function of the mass inside the cell unit (integrating, inside the porous wall), so that it fits the porous wall permeability that finally provides the pressure drop.

As soot aggregates in the exhaust gases are not spherical but characterised by irregularity, which is usually quantified by the fractal dimension [26], it is proposed a model where $\rho_{s, w}$ represents the density of soot aggregates inside the porous substrate, i.e. collected inside the cell unit. The apparent density of the soot in the cell unit, which is function of the hydrodynamic diameter of the collector unit along the loading process, is obtained multiplying $\rho_{s, w}$ by a shape factor. According to this proposal, $d_{c, w}$ is then given by Eq. 13 


$$
d_{c, w}=2\left(\frac{d_{c, w_{0}}^{3}}{8}+\frac{3 m_{s_{c e l l}}}{4 \pi \chi \rho_{s, w}}\right)^{\frac{1}{3}},
$$

being $\chi$ the collector unit shape factor, which ranges in the interval $0<\chi \leq 1$. Low $\chi$ suits for an irregular deposition of aggregates particles around the collector unit whereas $\chi=1$ would correspond to a perfect spherical growth of the collector unit.

The variation of the collector unit diameter as the porous wall is loaded involves the change of the parameters defining the porous structure of the substrate, i.e. porosity, mean pore diameter and permeability. Taking into account that the diameter of the cell unit is constant, then

$$
d_{c e l l, w}=\frac{d_{c, w_{0}}}{\left(1-\varepsilon_{w_{0}}\right)^{\frac{1}{3}}}=\frac{d_{c, w}}{\left(1-\varepsilon_{w}\right)^{\frac{1}{3}}},
$$

so that the porosity during the soot loading process is obtained as

$$
\varepsilon_{w}=1-\frac{d_{c, w}^{3}}{d_{c e l l, w}^{3}} .
$$

The values of $\varepsilon_{w}$ and $d_{c, w}$ yield the mean pore diameter as

$$
d_{p, w}=\frac{2}{3} \frac{\varepsilon_{w}}{1-\varepsilon_{w}} d_{c, w}
$$

and finally, the permeability of the porous substrate is calculated from the values of $\varepsilon_{w}, d_{c, w}$ considering also the corresponding value of the Stokes-Cunningham factor for the soot loading condition:

$$
k_{w}=f\left(\varepsilon_{w}\right) d_{c, w}^{2} S C F_{w}
$$

\section{Particulate layer permeability}

The filtration phase controlled in pressure drop by the deposition of soot particles inside the porous wall is known as deep bed filtration regime. Assuming spherical growth of the collector unit, this phase is considered to be finished when the saturation coefficient, which is defined as Eq. 18 shows, takes value 1.

$$
\phi=\frac{d_{c, w}^{3}-d_{c, w_{0}}^{3}}{\left(\psi d_{c e l l, w}\right)^{3}-d_{c, w_{0}}^{3}}
$$

The saturation coefficient determines the prevalence of the cake filtration regime. In Eq. $18 \psi$ is the percolation factor which defines the onset of pore bridging. The value of the percolation factor is usually estimated from experimental data to setup the model although it may be estimated by discrete particle dynamics deposition using the methods described by Konstandopoulos in [27]. 
Once the cake filtration regime governs, the pressure drop across the DPF is function of the micro-structural properties of the particulate layer. As in the case of the porous wall, the particulate layer is assumed to be a bed of spherical particles. Therefore, its permeability is a function of its porosity, the characteristic collector unit and the flow properties through the correction due to the slip flow effect:

$$
k_{p l}=f\left(\varepsilon_{p l}\right) d_{c, p l}^{2} S C F_{p l}
$$

In this case the Stokes-Cunningham factor is calculated from the Knudsen number referred to the gas mean free path and the mean pore diameter of the particulate layer:

$$
\begin{gathered}
K n_{p l}=\frac{2 \lambda}{d_{p, p l}} \\
d_{p, p l}=\frac{2}{3} \frac{\varepsilon_{p l}}{1-\varepsilon_{p l}} d_{c, p l}
\end{gathered}
$$

\section{Methodology and calculation hypothesis}

The model proposed in section 3 would allow the step by step calculation of the permeability in the porous wall with axial resolution if it was coupled with a soot filtration model to determine the collected soot mass, as those proposed by Liu [28] to study motion of nanoparticles in the inlet channels; Tandon [29], whose model focuses on filtration efficiency prediction; or Bollerhoff [30], who applies a filtration efficiency model as tool to evaluate performance of inhomogeneous porous wall structures. Hence, it is possible to predict the DPF pressure drop during the deep bed filtration regime. In the case of the cake filtration regime, it is necessary to estimate the porosity and the characteristic collector diameter to fit permeability-pressure drop models and experimental data. In this regard, Konstandopoulos [16, 31] has explored the relation between micro-structural particulate layer properties and DPF pressure drop response; in the same way, Haralampous and Koltsakis [32] have shown the need to assume an order of magnitude for particulate layer porosity to analyse the temperature gradient in the particulate layer and porous wall during the regeneration process. There is still a lack of predictive tools for such properties and the modelling of the cake growth is very expensive computationally and dependent on engine operating conditions, characteristics of the engine emission, etc.

Another application of the proposed model is the calculation of the pressure drop across DPFs for a given soot loading when installed in an engine whose performance must be predicted [33]. In this case the objective is not the modelling of the loading process, which would depend on the accuracy and robustness of the filtration model and on the engine operation history, which could be even unknown in modelling purposes. Therefore, it is advisable, and one of the objectives of this work, to provide a figure of the order of magnitude of the parameters controlling the pressure drop in loaded DPFs and their dependence on available or confident-predicted data. It will lead to an accurate pressure 
drop prediction, the main physical phenomenon in the DPF affecting the engine performance, besides heat transfer in specific pre-turbo DPF architectures [34].

The use of the model in this kind of application requires to consider some hypothesis regarding the filtration process resulting in the loaded DPF. The following hypothesis are taken to share the soot mass out between the porous wall and the particulate layer for any soot mass:

1. The loading process is divided into two phases:

- Deep bed filtration, during which it is assumed that soot particulates are only deposited inside the porous wall.

- Cake filtration, during which it is assumed that soot particulates only contributes to the growth of the particulate layer thickness.

The switch from deep bed to cake filtration regime is given by the saturation soot mass. It is defined as the soot mass collected in the monolith at which there is a drop in the pressure drop rate increase.

2. The value of the percolation factor has been set to 0.92 as representative value, according to literature data [16].

3. The packing density of soot inside the porous wall has been set to $50 \mathrm{~kg} / \mathrm{m}^{3}$ and $345 \mathrm{~kg} / \mathrm{m}^{3}$ respectively in order to discuss the influence of this parameter. According to the soot morphology abacus presented by Lapuerta $e t$ al. from TEM images [26], $\rho_{s, w}=50 \mathrm{~kg} / \mathrm{m}^{3}$ is a low value for soot aggregates. It would correspond to a range of aggregates from low fractal dimension with a slightly higher number of primary particles than the mean value $\left(\bar{n}_{p o} \approx 81\right)$ up to mean value fractal dimension $\left(\bar{D}_{f} \approx 1.87\right)$ combined with a low number of particles. As higher value has been set $\rho_{s, w}=345 \mathrm{~kg} / \mathrm{m}^{3}$, which is the density of soot aggregates with medium fractal dimension and medium number of primary particles obtained by Lapuerta et al. [26] assuming the carbon density to be $2000 \mathrm{~kg} / \mathrm{m}^{3}$. The choice of these extreme values of $\rho_{s, w}$ to setup the model allows evaluating its influence on the porous wall micro-scale description under loading conditions.

4. Penetration of soot mass inside the porous wall is only partial in wall-flow monoliths. It has been concluded from experimental works performed at the early developments of wall-flow DPF by Murtagh et al. [35] and in recent works conducted to analyse the influence of filtration velocity on soot loading characteristics [36] and to propose new analysis techniques of loaded DPFs [37]. Lattice Boltzmann computation has also reported similar results in different studies focused on soot accumulation and pore structure [38], soot deposition and combustion [39] or development of fuel efficient DPFs [40].

To obtain an approximation of the soot mass penetration, the DPF saturation mass is shared out in the required number of cell units from the inlet channel surface towards the outlet channel surface, so that all of them are completely satutared. By contrast, the remainder cell units remain completely clean. The saturation mass in a cell unit is given by

$$
m_{s, \text { sat cell }}=\frac{4}{3} \pi\left(\left(\frac{\psi d_{c e l l, w}}{2}\right)^{3}-\left(\frac{d_{c, w_{0}}}{2}\right)^{3}\right) \rho_{s, w}
$$


so that the number of saturated cell units is obtained as

$$
n_{\text {cell }, \text { sat }}=\frac{m_{s, \text { sat }}}{m_{s, \text { sat }}} .
$$

Dividing $n_{\text {cell,sat }}$ into the total number of cell units in the porous media provides the fraction of porous wall that is saturated, i.e. the soot penetration thickness.

Once defined the soot penetration thickness, the model divides the porous wall into two sections: from the inlet channel surface up to the penetration thickness the collected soot mass is uniformly distributed in the cell units up to reach the saturation mass; from the soot penetration thickness up to the outlet channel surface the porous wall is assumed to remain clean. Therefore, the effective porous wall permeability is given by

$$
\begin{aligned}
& \Delta p= \frac{\mu_{o} u_{w_{o}} w_{w}}{k_{w, e}}= \\
& \frac{\mu_{o} u_{w_{o}} w_{w} f_{w, s a t}}{k_{w}}+\frac{\mu_{o} u_{w_{o}} w_{w}\left(1-f_{w, s a t}\right)}{k_{w_{0}}} \\
& k_{w, e}=\frac{k_{w} k_{w_{0}}}{f_{w, \text { sat }} k_{w_{0}}+\left(1-f_{w, \text { sat }}\right) k_{w}}
\end{aligned}
$$

where $f_{w, s a t}$ is the fraction of porous wall used by soot mass.

5. During the cake filtration phase, the soot mass is assumed to be uniformly distributed along the particulate layer in the inlet channels, so that a constant thickness of the particulate layer is set.

6. The pressure drop in the particulate layer is dependent on the porosity $\left(\varepsilon_{p l}\right)$ and the characteristic diameter of the collector units $\left(d_{c_{p l}}\right)$. These parameters determine the thickness of the particulate layer for a given soot mass, the particulate layer permeability and its variation when changing the gas properties because of the slip flow effect.

\section{Results and discussion}

In this section the pressure drop of different DPFs is modelled as function of the soot mass loading. The main characteristics of the considered DPFs are summarised in Table 1.

A discrete modelling of a deep bed and cake loading processes is performed, i.e. prediction of the pressure drop and mass flow across the DPF for a given soot mass loading. This procedure allows fitting perfectly the porous substrate permeability by means of the shape factor $\chi$ and subsequently the particulate layer permeability by means of its porosity and characteristic collector diameter. Therefore, the value of these setup parameters can be discussed and related to other operation parameters in order to identify dependencies with operation conditions.

Experimental and geometric data have been obtained from [35] for DPFs \#A to \#D and from [41] in the case of DPF \#E. Micro-scale properties shown in Table 1 of the porous wall in DPFs \#F and \#G have been obtained applying 
the experimental-theoretical methodology described by Payri et al. in [24]. The porous wall permeability has been computed for every DPF according to Eq. 6.

\subsection{Soot loading test analysis}

Figure 1 shows the comparison between experimental and modelled pressure drop as function of the collected soot mass for DPFs \#A to \#D. Experiments in Figure 1 were performed with $0.285 \mathrm{~kg} / \mathrm{s}$ in mass flow at $260^{\circ} \mathrm{C}$. More details of these soot loading tests can be found in [35]. Figure 2 represents the prediction of the model for DPF \#E considering different mass flows. Tests from which the experimental data of DPF \#E have been obtained are described in [41]. In order to show with accuracy the pressure drop at low soot mass loading a logarithmic scale has been chosen. The soot mass at which the porous wall becomes saturated and the particulate layer starts its growth has been marked with a vertical black line.

As observed in Figures 1 and 2, the model is able to predict with high accuracy the DPF pressure drop during both deep bed and cake filtration regimes, independently of the soot packing density inside the porous wall and mass flow respectively.

\subsubsection{Deep bed filtration regime}

Soot packing density inside the porous wall is setting the estimation of the soot penetration thickness and both are affecting the setup of the model through the value of the shape parameter $\chi$, which finally sets the pressure drop during the deep bed filtration regime. Once the cake filtration regime takes places $\chi$ keeps constant.

On the one hand, as the soot packing density inside the porous wall decreases the same soot mass uses more thickness inside the porous wall. This result is represented in Figure 3, which shows the dependence of the fraction of porous wall with soot penetration as function of $\rho_{s, w}$ and the mean pore diameter for DPFs \#A, \#B, \#C and \#D. Note that the porous wall porosity is very similar (48\%-50\%) for the represented DPFs and therefore its influence can be neglected.

In the case of imposing a low value of soot packing density $\left(\rho_{s, w}=50 \mathrm{~kg} / \mathrm{m}^{3}\right)$, the fraction of porous wall with soot penetration ranges from $15 \%$ to $40 \%$ and increases as the mean pore diameter does.

When $\rho_{s, w}$ is computed as the value of packing density of soot aggregates with mean fractal dimension and mean number of primary particles, i.e. $\rho_{s, w}=345 \mathrm{~kg} / \mathrm{m}^{3}$, the soot penetration results below $5 \%$ of the porous wall thickness even for very high mean pore diameter. This result is in good agreement with the conclusions highlighted in the study of Murtagh [35], in which soot penetration is studied by means of visualisation techniques. In this work the soot penetration was found to be minimal, specially in the case of DPFs \#A and \#D, which have the lower mean pore diameter and a very homogeneous pore size distribution. However, more extensive soot penetration was detected in DPFs \#B and \#C due to not only the higher mean pore diameter but also due to an heterogeneous pore size distribution, which is a characteristic that lumped porous wall models cannot take properly into account. Nevertheless, recent studies on experimental and computational characterisation of the loading process in wall-flow DPFs performed by 
several authors as Yapaulo [36], Fino [37] and Stewart [40] have reported a very superficial bulk soot penetration controlled by soot aggregates deposition [42]. Therefore, it can be concluded that in current DPF substrates, which are characterised by a very homogenous pore size distribution [43], the density of a mean soot aggregate can be considered as representative of the order of magnitude of soot packing density inside the porous wall $\left(\rho_{s, w}=345 \mathrm{~kg} / \mathrm{m}^{3}\right)$.

The increase in pressure drop during the deep bed filtration regime is only dependent on the porous wall permeability. Since the model works with meaningful values for soot packing density and soot penetration inside the porous wall, the setup of the model is only dependent on the shape factor for every soot mass. It allows fitting the effective porous wall permeability that sets the pressure according to the Darcy's equation. Figure 4 shows the value of the shape factor as function of the soot mass inside the porous wall up to its saturation in every DPF. Soot loading test for DPF \#F was performed by Lapuerta et al. [44] in a 21 passenger car engine. Operating point was a low-load mode (1667 rpm, $78 \mathrm{Nm}$ and $25 \%$ of EGR rate) belonging to the urban sub-cycle of the New European Driving Cycle (NEDC), with high soot emissions and therefore with high contribution to the DPF loading. For DPF modelling purpose, the parameters of interest are pressure drop as function of soot mass loading, mass flow, which is $0.0235 \mathrm{~kg} / \mathrm{s}$, and temperature, which ranges from $345^{\circ} \mathrm{C}$ to $380^{\circ} \mathrm{C}$ due to exhaust line thermal inertia [45]. The soot loading test of DPF \#G was performed at author's research centre in a 21 passenger car engine. The operating point was also selected from the urban sub-cycle of the NEDC. Engine was run at $2500 \mathrm{rpm}, 80 \mathrm{Nm}$ and $16 \%$ of EGR rate. Mass flow was $0.375 \mathrm{~kg} / \mathrm{s}$ and temperature ranged from $275^{\circ} \mathrm{C}$ to $320^{\circ} \mathrm{C}$ during the test because of the exhaust line thermal inertia. For both $\mathrm{DPF} \# \mathrm{~F}$ and $\# \mathrm{G}$, the pressure drop was measured with piezoresistive pressure sensors placed at the inlet and outlet of the DPFs.

Differences between plots (a) and (b) in Figure 4 are due to the influence of soot packing density inside the porous wall. Although from a soot penetration point of view, it has been already shown that the proper value for soot packing density inside the porous wall is that of the mean soot aggregate, it is of interest to discuss the dependence of the shape factor on several parameters.

The shape factor shows a linear increase as the soot mass inside the porous wall increases. This response means that the growth of the collector unit gains in uniformity with the soot mass increase, so that the hydrodynamic diameter of the collector unit and the geometric diameter assuming spherical growth would tend to coincide. It also means that the apparent density of soot inside the porous wall is not constant but controlled by the growth dynamics. It contrasts with other literature models where apparent soot packing density is set constant independently of soot mass from mathematical procedures based on non-linear regression [16]. This kind of solution usually imposes values out of order of magnitude with respect to raw soot emission which losses the physical insight of the solution. Figure 5 shows different states of the collector unit along the loading process. Plot (a) represents the case of a clean collector unit; plot (b) describes the case of an irregular growth around the collector unit with low soot mass leading to low shape factor; and plot (c) shows a saturated cell unit, which is characterised by a high shape factor.

Besides the linear increase of the shape factor as the soot mass increases it has been found that the shape factor profile of every of the considered DPFs collapses into a single trend, independently of the soot packing density inside 
the porous wall and the DPF characteristics. This correlation is a function of a soot density factor which is defined as the ratio between the soot packing density inside the porous wall and the soot mass to soot penetration volume ratio:

$$
\Phi_{\rho_{s}}=\frac{\rho_{s, w}}{m_{s} / V_{p}}
$$

The soot mass to soot penetration volume ratio $\left(m_{s} / V_{p}\right)$ represents the density of soot mass inside the porous wall if it was uniformly distributed into a void volume coinciding with the soot penetration volume $\left(V_{p}\right)$. It is defined as the volume of porous wall which is used by soot in the whole monolith, so that it is given by

$$
V_{p}=4 \alpha w_{w} L N_{i c} f_{w, s a t}
$$

where $L$ is the channel length and $N_{i c}$ represents the number of inlet channels.

Figure 6 shows in plot (a) a linear correlation between the shape factor and the soot mass to soot penetration volume ratio. It contents the effect of the soot mass and the soot penetration but the influence of the soot packing density inside the porous wall falls out. Finally, plot (b) represents the dependence of the shape factor on the soot density factor. It obeys to a potential function that is the same for every of the analysed DPFs:

$$
\chi=2.3136\left(\Phi_{\rho_{s}}\right)^{-0.864}
$$

This general result, which is shown to be applicable to state of the art wall-flow DPFs, and the use of representative properties of raw soot emission define a change in apparent soot packing density around collector units as soot mass loading varies. It provides predictive capability to the proposed pressure drop model for loaded porous wall in wallflow DPFs and no dependence on mathematical fitting procedures.

\subsubsection{Cake filtration regime}

Figure 1 and 2 show that the pressure drop is accurately reproduced by the model during the cake filtration regime. Figure 7 also confirms this result for DPFs \#F and \#G. The capability of the model during the cake filtration regime is dependent on the prediction of the porous wall permeability once reached the wall clogging, which has been already discussed, and on the prediction of the particulate layer permeability. According to Eq. 19-21, it depends on the porosity and the characteristic diameter of the collector unit besides the mean free path of the gas molecules.

Table 2 summarises the microstructural properties and the particulate layer density for DPFs \#A to \#G. It is shown that the characteristic diameter of the collector unit in the particulate layer, which is controlling the pressure drop, coincides with representative soot aggregate diameters. The experimental soot particles size distribution emitted by the engine during the DPF loading is not available for DPFs \#A to \#E, so that the collector diameter of the particulate layer have been setup. Nevertheless, all the values are inside the order of magnitude of the mode of the particles size distribution of raw soot emission in Diesel engines [46]. 
In the case of DPFs \#F and \#G, the diameter of the collector unit has been respectively set to the mode diameter corresponding to the particles size distribution emitted during the soot loading test, which is shown in Figure 8. For the selected operating points, the mode of particle size distribution is low comparing with standard Diesel engine emission, specially in the case of DPF \#G. However, the model setup shows that this parameter governs the particulate layer permeability.

The imposition of the collector unit diameter as the mode aggregate diameter leads to a particulate layer porosity ranging from 0.6 to 0.7 . The porosity and the collector unit diameter define the pore diameter that controls the slip-flow effect and finally sets the particulate layer permeability.

The porosity defines the density of the particulate layer, which ranges from $600 \mathrm{~kg} / \mathrm{m}^{3}$ to $800 \mathrm{~kg} / \mathrm{m}^{3}$ for DPFs \#A to \#G assuming the carbon density to be $2000 \mathrm{~kg} / \mathrm{m}^{3}$. This range is in very good agreement with the results obtained by Opris and Johnson [47] by means of an experimental and theoretical methodology. Additionally, the setup of the particulate layer porosity obtained in this work is inside the order of magnitude of the measurements of soot deposits porosity obtained in the studies of Rockne et al. [48]. However, particulate layer porosity applied in several works from Konstandopoulos [16, 31] is around 0.95 . This value is obtained from the model setup to the experimental pressure drop. In these works, the permeability and the SCF in the particulate layer are referred to the primary particles diameter. It contrasts with the model proposed in section 4 where the mode of the particles size distribution for permeability and the mean pore diameter of the particulate layer for the SCF are respectively applied instead of the diameter of primary particles. The mean pore diameter is the one defining the slip-flow effect on the gas flow path, like analogously applied in the porous wall as proposed by Johnson et al. [49] and confirmed by Payri et al. in clean wall-flow DPFs [24].

On the other hand, according to the results of experimental studies performed in Diesel engines by different authors, like Zhu et al. [50], Neer and Koylu [51] and Lapuerta et al. [26], the porosity of mean soot aggregates is around $0.81\left(\bar{D}_{f}=1.9, \bar{n}_{p 0}=80\right)$. It results clearly lower than 0.95 . Thus, taking as reference the porosity of mean soot aggregates and the influence of ballistic deposition and pressure difference across the particulate layer, which lead to higher particulate layer compaction as pointed out from experimental data by Konstandopoulos et al. [52] and Lapuerta et al. [44], the reported order of magnitude of the particulate layer porosity [0.6, 0.7] is justified. This result underlines the suitability of the proposed particulate layer model to work with meaningful physical values for the involved magnitudes beyond the use of fitting mathematical procedures.

\subsection{Cold flow gas stand test analysis}

In order to confirm the validity of the micro-structure description given in previous sections and further justify the mean aggregates as collector units in the particulate layer (being the mean pore diameter they form which sets the slip flow correction in this layer), DPFs \#F and \#G have been tested in a gas stand. Tests have been performed at room temperature $\left(20^{\circ} \mathrm{C}\right)$ with the maximum soot loading respectively shown in Figure 7 . Figure 9 shows the set-up of the gas stand schematically. After the installation of the loaded DPF, tests were performed ranging the mass flow 
rate between $0.022 \mathrm{~kg} / \mathrm{s}$ and $0.111 \mathrm{~kg} / \mathrm{s}$ to measure the pressure drop across the DPF at a wide range of flow regimes. Tests were carried out under aspiration conditions for DPF \#F, i.e. inducing a pressure decrease in the settling volume by means of a roots blower, and under impulsion conditions for DPF \#G, i.e. increasing pressure at the inlet of the DPF by means again of the roots blower. The air mass flow rate was measured with a hot film anemometer whereas the pressure drop was measured with a water column connected to the settling volume.

The interest for this kind of test lies on the fact that the model has to predict the change in porous substrate and particulate layer permeability, to predict in turn the DPF pressure drop. The main reason for these changes is the variation in temperature between the soot loading test, from which the model has been setup, and the gas stand test. In addition, the test of the DPF at different mass flow determines different gas densities due to the different pressure drop and hence different kinematic viscosity. Changes in temperature and kinematic viscosity affect the gas mean free path and therefore the Knudsen number and the slip flow correction. If the mean pore diameter in every porous medium was not correctly defined from the soot loading test data it would lead to wrong values of SFC and then permeability in the analysis of the gas stand test.

Figure 10 shows the prediction of mass flow across the DPF as function of the experimental pressure drop measured in the gas stand for DPFs \#F and \#G. Comparison with experimental mass flow shows a very good prediction in the case of DPF \#F. A slight underprediction of mass flow across DPF \#G is found although the trend is perfectly caught all along the tested range.

The prediction of the permeability in the porous wall and the particulate layer is also shown in Figure 10 as function of the experimental pressure drop for every DPF. These values are compared with the corresponding ones obtained in the modelling of the soot loading test. The merit of the model is in the calculation of the permeabilities since the mass flow prediction is dependent on the models capability to account for the permeability change caused by the slip flow effect, which is dependent on gas temperature and kinematic viscosity.

As previously explained, DPF \#F was tested in the gas stand under aspiration conditions by means of a roots blower reducing the pressure at the outlet of the DPF. As a consequence, density change at the inlet is very low and only governed by static conditions decrease as mass flow increases. Hence porous wall and particulate layer permeabilities are almost constant with mass flow being the difference with the soot loading test only dependent on gas temperature variation. On the other hand, DPF \#G was tested under impulsion conditions, so that pressure was increased at the inlet of the DPF by means of the roots blower for every mass flow. It produces the gas density increase at the DPF inlet. Consequently, the permeability is reduced as mass flow increases both in porous wall and particulate layer and differences with respect to the soot loading test also increases.

\section{Summary and conclusions}

A model to predict pressure drop in wall-flow DPFs as function of soot mass loading and flow properties has been presented. A packed bed of spherical particles approach has been developed to describe the mean properties of the 
micro-scale in the porous media of wall-flow DPFs. It makes possible to predict the permeability both in the porous wall and the particulate layer. These properties are then integrated by means of the Darcy's equation into the gas governing equations for one-dimensional unsteady compressible flow transport across the inlet and outlet channels.

The model is mainly devoted to the pressure drop prediction in applications based on a discrete initial condition without dependence on previous operation history, such as engine performance or DPF regeneration analysis. Hence it is assumed that soot mass is uniformly distributed and that during deep bed filtration regime all the soot mass is deposited inside the porous wall. These are the main hypothesis of the work, which could be substituted by a filtration efficiency model in other applications where considered worth higher detail in the soot distribution.

The prediction of the pressure drop during the deep bed filtration regime has shown that the soot packing density inside the porous wall is well represented by density of soot aggregates with mean fractal dimension. It allows properly predicting the soot penetration thickness inside the porous wall when the saturation soot mass is reached. The obtained results have shown to be in agreement with both experimental and Lattice Boltzmann modelling data available in the literature.

The increasing pressure drop during deep bed filtration regime is dependent on the soot mass inside the unit cells but also on the growth dynamics of the collector unit. This effect is considered by means of a shape factor, which correlates with a potential function of a soot density factor. It is in turn defined as function of the soot mass, the soot penetration volume and the soot packing density inside the porous wall for state of the art wall-flow DPFs. The shape factor and the soot packing density inside the porous wall set the change in apparent soot packing density around collector units as soot mass loading varies. This characteristic provides the model predictive capability for pressure drop in loaded porous walls of wall-flow DPFs and removes the need to resort to setup mathematical fitting procedures.

The permeability of the particulate layer is obtained from the effective porosity, the characteristic collector diameter and the mean pore diameter, to which is referred the slip flow correction. This approach points out that the characteristic collector diameter coincides with that of the mode of soot particle emission. The use of mean raw emission properties is shown again to be suitable when it is analysed the effect on the value taken by other parameters required to define the pressure drop. It is the case of the effective porosity of the particulate layer, which ranges from 0.6 to 0.7 in the analysed DPFs. It has been discussed that this result is in agreement with the porosity of soot deposits measured by several authors and also with the slightly higher values of porosity indicated in the literature for soot aggregates, whose compaction during the deposition process defines the porosity of the particulate layer.

The validity of the porous wall and particulate layer micro-structure description is finally strengthened by the prediction of mass flow as function of the pressure drop when the DPFs are subjected to different gas temperature than in the soot loading tests. This kind of test, which is performed in a gas stand at room temperature, determines the capability of the model to account for the slip flow effect, which is ultimately dependent on the definition of the mean pore diameter, i.e. dependent on the porosity and collector unit diameter in the porous wall and the particulate layer. The good results obtained highlight that the slip flow correction is effectively dependent on the mean pore diameter of 
the porous wall and the particulate layer. In the case of the particulate layer, this conclusion verifies that the diameter of the collector unit is closely related to that of the mode of the particle size distribution, since it determines in turn the mean pore diameter in this porous medium.

\section{Acknowledgements}

This work has been partially supported by the Vicerrectorado de Investigación de la Universitat Politènica de València through grant number SP20120340-UPPTE/2012/96.

\section{References}

[1] J. L. Sullivan, R. E. Baker, B. A. Boyer, R. H. Hammerle, T. E. Kenney, L. Muniz, T. J. Wallington, $\mathrm{CO}_{2}$ emission benefit of diesel (versus gasoline) powered vehicles, Environmental Science and Technology 38(12) (2004) 3217-3223.

[2] E. Zervas, S. Poulopoulos, C. Philippopoulos, $\mathrm{CO}_{2}$ emissions change from the introduction of Diesel passenger cars: Case of Greece, Energy 31(14) (2006) 2915-2925.

[3] F. Payri, V. Bermúdez, R. Payri, F. J. Salvador, The influence of cavitation on the internal flow and the spray characteristics in diesel injection nozzles, Fuel 83 (2004) 419-431.

[4] A. J. Torregrosa, A. Broatch, R. Novella, L. F. Mónico, Suitability analysis of advanced diesel combustion concepts for emissions and noise control, Energy 36 (2) (2011) 825-838.

[5] D. C. Rakopoulos, C. D. Rakopoulos, E. G. Giakoumis, A. M. Dimaratos, Characteristics of performance and emissions in high-speed direct injection Diesel engine fueled with diethyl ether/diesel fuel blends, Energy 43(1) (2012) 214-224.

[6] N. Yilmaz, Comparative analysis of biodiesel-ethanol-diesel and biodiesel-methanol-diesel blends in a Diesel engine, Energy 40(1) (2012) 210-213.

[7] J. Galindo, J. R. Serrano, H. Climent, O. Varnier, Impact of two-stage turbocharging architectures on pumping losses of automotive engines based on an analytical model, Energy Conversion and Management 51(10) (2010) 1958-1969.

[8] N. Ishikawa, A study on emissions improvement of a Diesel engine equipped with a mechanical supercharger, International Journal of Engine Research 13 (2012) 99-107.

[9] V. Bermúdez, J. M. Luján, B. Pla, W. G. Linares, Effects of low pressure exhaust gas recirculation on regulated and unregulated gaseous emissions during NEDC in a light-duty Diesel engine, Energy 36 (9) (2011) 5655-5665.

[10] A. Pesiridis, The application of active control for turbocharger turbines, International Journal of Engine Research 13(4) (2012) 385-398.

[11] O. Salvat, P. Marez, G. Belot, Passanger car serial application of a particulate filter system on a common-rail, direct-injection Diesel engine, in: SAE Technical Paper 2000-01-0473, 2000.

[12] A. J. Torregrosa, J. R. Serrano, F. J. Arnau, P. Piqueras, A fluid dynamic model for unsteady compressible flow in wall-flow diesel particulate filters, Energy 36 (2011) 671-684.

[13] V. Bermúdez, J. R. Serrano, P. Piqueras, O. García-Afonso, Assessment by means of gas dynamic modelling of a pre-turbo diesel particulate filter configuration in a turbocharged HSDI Diesel engine under full-load transient operation, Proceedings of the Institution of Mechanical Engineers, Part D: Journal of Automobile Engineering 225 (9) (2011) 1134-1155.

[14] P. Tourlonias, G. C. Koltsakis, Model-based comparative study of Euro 6 diesel aftertreatment concepts, focusing on fuel consumption, International Journal of Engine Research 12 (2011) 238-251.

[15] M. Masoudi, Hydrodynamics of diesel particulate filters, in: SAE Technical Paper 2002-01-1016, 2002.

[16] A. G. Konstandopoulos, M. Kostoglou, E. Skaperdas, E. Papaioannou, D. Zarvalis, E. Kladopoulou, Fundamental studies of diesel particulate filters: transient loading, regeneration and aging, in: SAE Technical Paper 2000-01-1016, 2000. 
[17] O. A. Haralampous, G. C. Koltsakis, Back-diffusion modeling of $\mathrm{NO}_{2}$ in catalyzed diesel particulate filters, Industrial and Engineering Chemistry Research 43(4) (2004) 875-883.

[18] Openwam website, CMT-Motores Térmicos (Universitat Politècnica de València). www.openwam.org (2013).

[19] J. Galindo, J. R. Serrano, F. J. Arnau, P. Piqueras, Description of a Semi-Independent Time Discretization methodology for a one-dimensional gas dyanmics model, Journal of Engineering for Gas Turbines and Power 131 (2009) 034504.

[20] J. Galindo, J. R. Serrano, P. Piqueras, O. García-Afonso, Heat transfer modelling in honeycomb wall-flow diesel particulate filters, Energy 43 (2012) 201-213.

[21] J. R. Serrano, F. J. Arnau, P. Piqueras, O. García-Afonso, Application of the two-step Lax\&Wendroff-FCT and the CE-SE method to flow transport in wall-flow monoliths, International Journal of Computer Mathematics (2013), DOI: 10.1080/00207160.2013.783206.

[22] J. M. Desantes, J. R. Serrano, F. J. Arnau, P. Piqueras, Derivation of the method of characteristics for the fluid dynamic solution of flow advection along porous wall channels, Applied Mathematical Modelling 36(7) (2012) 3134-3152.

[23] A. G. Konstandopoulos, J. H. Johnson, Wall-flow diesel particulate filters - Their pressure drop and collection efficiency, in: SAE Technical Paper 890405, 1989.

[24] F. Payri, A. Broatch, J. R. Serrano, P. Piqueras, Experimental-theoretical methodology for determination of inertial pressure drop distribution and pore structure properties in wall-flow diesel particulate filters (DPFs), Energy 36 (2011) 6731-6744.

[25] S. Kuwabara, The forces experienced by randomly distributed parallel circular cylinders or spheres in a viscous fluid at small Reynolds numbers, Journal of the Physical Society of Japan 14 (1959) 527-532.

[26] M. Lapuerta, R. Ballesteros, F. J. Martos, A method to determine the fractal dimension of diesel soot agglomerates, Journal of Colloid and Interface Science 303 (2006) 149-158.

[27] A. G. Konstandopoulos, Deposit growth dynamics: particle sticking and scattering phenomena, Powder Technology 109 (2000) $262-277$.

[28] Y. Liu, J. Gong, J. Fu, H. Cai, G. Long, Nanoparticle motion trajectories and deposition in an inlet channel of wall-flow diesel particulate filter,Journal of Aerosol Science 40(4) (2009) 307-323.

[29] P. Tandon, A. Heibel, J. Whitmore, N. Kekre, K. Chithapragada, Measurement and prediction of filtration efficiency evolution of soot loaded diesel particulate filters, Chemical Engineering Science 65 (2010) 4751-4760.

[30] T. Bollerhoff, I. Markomanolakis, G. C. Koltsakis, Filtration and regeneration modeling for particulate filters with inhomogeneous wall structure, Catalysis Today 188 (2012) 24-31.

[31] A. G. Konstandopoulos, E. Skaperdas, M. Masoudi, Microstuctural properties of soot deposits in diesel particulate traps, in: SAE Technical Paper 2002-01-1015, 2002.

[32] O. A. Haralampous, G. C. Koltsakis, Intra-layer temperature gradients during regeneration of diesel particulate filters, Chemical Engineering Science 57(13) (2002) 2345-2355.

[33] V. Bermúdez, J. R. Serrano, P. Piqueras, O. García-Afonso, Influence of DPF soot loading on engine performance with a pre-turbo aftertreatment exhaust line, in: SAE Technical Paper 2012-01-0362, 2012.

[34] V. Bermúdez, J. R. Serrano, P. Piqueras, O. García-Afonso, Analysis of heavy-duty turbocharged Diesel engine response under cold transient operation with a pre-turbo aftertreatment exhaust manifold configuration, International Journal of Engine Research, doi:10.1177/1468087412457670.

[35] M. J. Murtagh, D. L. Sherwood, L. S. Socha, Development of a diesel particulate filter composition and its effect on thermal durability and filtration performance, in: SAE Technical Paper 940235, 1994.

[36] R. A. Yapaulo, E. Wirojsakunchai, T. Orita, D. E. Foster, M. Akard, L. R. Walker, M. J. Lance, Impact of filtration velocities and particulate matter characteristics on diesel particulate filter wall loading, International Journal of Engine Research 10 (5) (2009) 287-304.

[37] D. Fino, N. Russo, F. Millo, D. S. Vezza, F. Ferrero, A. Chianale, New tool for experimental analysis of diesel particulate filter loading, Top Catalysis 52 (2009) 13-20.

[38] K. Yamamoto, S. Satake, H. Yamashita, N. Takada, M. Misawa, Lattice-Boltzmann simulation on porous structure and soot accumulation, Mathematics and Computers in Simulation 72 (2006) 257-263. 
[39] K. Yamamoto, A. Oohori, H. Yamashita, S. Daido, Simulation on soot deposition and combustion in diesel particulate filter, Proceedings of the Combustion Institute 32 (2009) 1965-1972.

[40] M. L. Stewart, T. R. Gallant, D. H. Kim, G. D. Maupin, A. Zelenyuk, Fuel efficient diesel particulate filter (DPF) modeling and development, in: Pacific Northwest National Laboratory, PNNL-19476, 2010.

[41] G. Gaiser, P. Mucha, Prediction of pressure drop in diesel particulate filters considering ash deposit and partial regeneration, in: SAE Technical Paper 2004-01-0158, 2004.

[42] A. Liati, P. D. Eggenschwiler, Characterization of particulate matter deposited in diesel particulate filters: Visual and analytical approach in macro-, micro- and nano-scales, Combustion and Flame 157(9) (2010) 1658-1670.

[43] M. J. Murtagh, Diesel particulate filters (DPF): A short course, in: Diesel particulate and NOx emissions course, University of Leeds, Ann Arbor, MI, 2002.

[44] M. Lapuerta, F. Oliva, S. Martínez-Martínez, Modeling of the soot accumulation in DPF under typical vehicle operating conditions, SAE International Journal of Fuels and Lubricants 3(2) (2010) 532-542.

[45] F. Oliva, Estudio sobre los procesos de acumulación y regeneración de hollín en una trampa de partículas diésel con diferentes combustibles, Ph.D. thesis, text in spanish, Universidad de Castilla-La Mancha (2012).

[46] D. B. Kittelson, Engines and nanoparticles, a review, Journal of Aerosol Science 29 (5-6) (1998) 575-588.

[47] C. N. Opris, J. H. Johnson, A 2-D computational model describing the flow and filtration characteristics of a ceramic diesel particulate trap, in: SAE Technical Paper 980545, 1998.

[48] K. J. Rockne, G. L. Taghon, D. S. Kosson, Pore structure of soot deposits from several combustion sources, Chemosphere 41 (2000) 11251135 .

[49] H. Mohammed, A. P. Triana, S. L. Yang, J. H. Johnson, An advanced 1D 2-layer catalized diesel particulate filter model to simulate: filtration by the wall and particulate cake, oxidation in the wall and particulate cake by $\mathrm{NQ}$ and $\mathrm{O}_{2}$ and regeneration by heat addition, in: SAE Technical Paper 2006-01-0467, 2006.

[50] J. Zhu, K. O. Lee, A. Yozgatligil, M. Y. Choi, Effects of engine operating conditions on morphology, microstructure, and fractal geometry of light-duty Diesel engine particulates, Proceedings of the Combustion Institute 30(2) (2005) 2781-2789.

[51] A. Neer, U. O. Koylu, Effect of operating conditions on the size, morphology, and concentration of submicrometer particulates emitted from a Diesel engine, Combustion and Flame 146 (2006) 142-154.

[52] A. G. Konstandopoulos, M. Kostoglou, N. Vlachos, E. Kladopoulo, Progress in diesel particulate filter simulation, in: SAE Technical Paper 2005-01-0946, 2005.

\section{Nomenclature}

$\begin{array}{ll}d_{c} & \text { collector unit diameter } \\ d_{c e l l} & \text { cell unit diameter } \\ d_{p} & \text { mean pore diameter } \\ D & \text { diameter } \\ \bar{D}_{f} & \text { mean fractal diameter of soot aggregates } \\ e_{0} & \text { specific stagnation internal energy } \\ f_{w, s a t} & \text { saturated fraction of porous wall thickness } \\ F & \text { area } \\ F_{w} & \text { momentum transfer coefficient for square channels }\end{array}$




$\begin{array}{ll}h_{0} & \text { specific stagnation enthalpy } \\ k_{p l} & \text { particulate layer permeability } \\ k_{w} & \text { porous wall permeability } \\ k_{w, e} & \text { effective porous wall permeability } \\ K n & \text { Knudsen number } \\ L & \text { channel length } \\ m_{s} & \text { soot mass } \\ m_{s_{c e l l}} & \text { soot mass in a cell unit } \\ m_{s, s a t} & \text { soot mass saturating the porous wall } \\ m_{s, s a t_{c e l l}} & \text { soot mass saturating a cell unit } \\ n_{\text {cell,sat }} & \text { number of saturated cell units } \\ \bar{n}_{p o} & \text { mean number of primary particles in soot aggregates } \\ N_{i c} & \text { number of inlet channels } \\ p & \text { pressure } \\ q & \text { heat per unit of time and mass } \\ t & \text { time } \\ u & \text { velocity } \\ u_{w} & \text { filtration velocity } \\ V_{p} & \text { soot penetration volume } \\ w_{p l} & \text { particulate layer thickness } \\ w_{w} & \text { axial dimension } \\ x & \end{array}$

\section{Greek letters}

$\begin{array}{ll}\alpha & \text { honeycomb cell size } \\ \chi & \text { shape factor } \\ \Delta p & \text { pressure drop } \\ \varepsilon & \text { porosity } \\ \phi & \text { porous wall saturation coefficient } \\ \Phi_{\rho_{s}} & \text { soot density factor } \\ \lambda & \text { gas mean free path } \\ \mu & \text { dynamic viscosity } \\ \rho & \text { gas density } \\ \rho_{s, w} & \text { soot packing density inside the porous wall }\end{array}$




$$
\begin{array}{ll}
\sigma & \text { cell density } \\
\psi & \text { percolation factor }
\end{array}
$$

$\begin{array}{ll}\text { Subscripts } & \\ i & \text { inlet channel } \\ o & \text { outlet channel } \\ p l & \text { referred to the particulate layer } \\ w & \text { referred to the porous wall } \\ w 0 & \text { referred to the clean porous wall }\end{array}$

$\begin{array}{ll}\text { Abbreviations } & \\ \text { DPF } & \text { Diesel particulate filter } \\ \text { NEDC } & \text { New European Driving Cycle } \\ \text { SCF } & \text { Stokes-Cunningham factor }\end{array}$

\section{List of Tables}

- Table 1.- Characteristics of analysed DPFs.

- Table 2.- Micro-scale properties of the particulate layer in every DPF.

\section{List of Figures}

- Figure 1.- Modelling of pressure drop vs. soot mass for DPFs \#A, \#B, \#C and \#D assuming $\rho_{s, w}$ equal to $50 \mathrm{~kg} / \mathrm{m}^{3}$ and $345 \mathrm{~kg} / \mathrm{m}^{3}$.

- Figure 2.- Modelling of pressure drop vs. soot mass for DPF \#E as function of the mass flow across the DPF at ambient conditions.

- Figure 3.- Fraction of porous wall with soot penetration for DPFs \#A, \#B, \#C and \#D assuming $\rho_{s, w}$ equal to $50 \mathrm{~kg} / \mathrm{m}^{3}$ and $345 \mathrm{~kg} / \mathrm{m}^{3}$.

- Figure 4.- Shape factor as function of collected soot mass inside the porous wall for every DPF.

- Figure 5.- Sketch of collector diameter growth in a cell unit as the soot mass inside the porous wall increases.

- Figure 6.- Shape factor correlation with soot density factor $\Phi_{\rho_{s}}$.

- Figure 7.- Modelling of pressure drop vs. soot mass for DPFs \#F and \#G.

- Figure 8.- Particle size distribution emitted upstream of the DPFs \#F and \#G during the soot loading test.

- Figure 9.- Scheme of the gas stand to characterise pressure drop in loaded DPFs \#F and \#G at room temperature as function of mass flow.

- Figure 10.- Mass flow prediction as function of pressure drop in gas stand at $20^{\circ} \mathrm{C}$ for DPFs \#F and \#G. Comparison between porous wall and particulate layer permeability in this test and the corresponding to the soot loading test. 
Table 1: Characteristics of analysed DPFs.

\begin{tabular}{lcccccccc}
\hline \hline & & \#A [35] & $\# \mathrm{~B}[35]$ & $\# \mathrm{C}[35]$ & $\# \mathrm{D}[35]$ & $\# \mathrm{E}[41]$ & $\# \mathrm{~F}$ & $\# \mathrm{G}$ \\
\hline Substrate & & Cord. & Cord. & Cord. & Cord. & $\mathrm{SiC}$ & $\mathrm{SiC}$ & $\mathrm{SiC}$ \\
$L$ & {$[\mathrm{~m}]$} & 0.305 & 0.305 & 0.305 & 0.305 & 0.15 & 0.22 & 0.2 \\
$D$ & {$[\mathrm{~m}]$} & 0.267 & 0.267 & 0.267 & 0.267 & 0.1437 & 0.126 & 0.132 \\
$\sigma$ & {$[\mathrm{cpsi}]$} & 100 & 100 & 100 & 100 & 200 & 285 & 200 \\
$\alpha$ & {$[\mathrm{mm}]$} & 2.11 & 2.11 & 2.11 & 2.11 & 1.44 & 1.3 & 1.486 \\
$w_{w}$ & {$[\mathrm{~mm}]$} & 0.43 & 0.43 & 0.43 & 0.43 & 0.35 & 0.2 & 0.31 \\
$\varepsilon_{w_{0}}$ & {$[\%]$} & 50 & 50 & 50 & 48 & 41 & 46 & 41.5 \\
$d_{p, w_{0}}$ & {$[\mu \mathrm{m}]$} & 13.4 & 24.4 & 34.1 & 12.5 & 32.85 & 20.2 & 12 \\
$k_{w_{0}}$ & {$\left[x 10^{-13} \mathrm{~m}^{2}\right]$} & 3.44 & 11.6 & 22.54 & 3 & 18.3 & 7.61 & 2.49 \\
\hline \hline
\end{tabular}

Table 2: Micro-scale properties of the particulate layer in every DPF.

\begin{tabular}{ccccc}
\hline \hline DPF & $\varepsilon_{p l}[-]$ & $d_{c, p l}[\mu \mathrm{m}]$ & $\rho_{p l}\left[\mathrm{~kg} / \mathrm{m}^{3}\right]$ & $k_{p l}\left[\mathrm{~m}^{2}\right]$ \\
\hline \#A & 0.67 & 102 & 660 & $1.65 \times 10^{-15}$ \\
\#B & 0.68 & 100 & 640 & $1.64 \times 10^{-15}$ \\
\#C & 0.67 & 95 & 660 & $1.45 \times 10^{-15}$ \\
\#D & 0.7 & 110 & 600 & $2.09 \times 10^{-15}$ \\
\#E & 0.6 & 95 & 800 & $5.79 \times 10^{-16}$ \\
\#F & 0.6 & 85 & 800 & $1.07 \times 10^{-15}$ \\
\#G & 0.6 & 69 & 800 & $7.97 \times 10^{-16}$ \\
\hline \hline
\end{tabular}



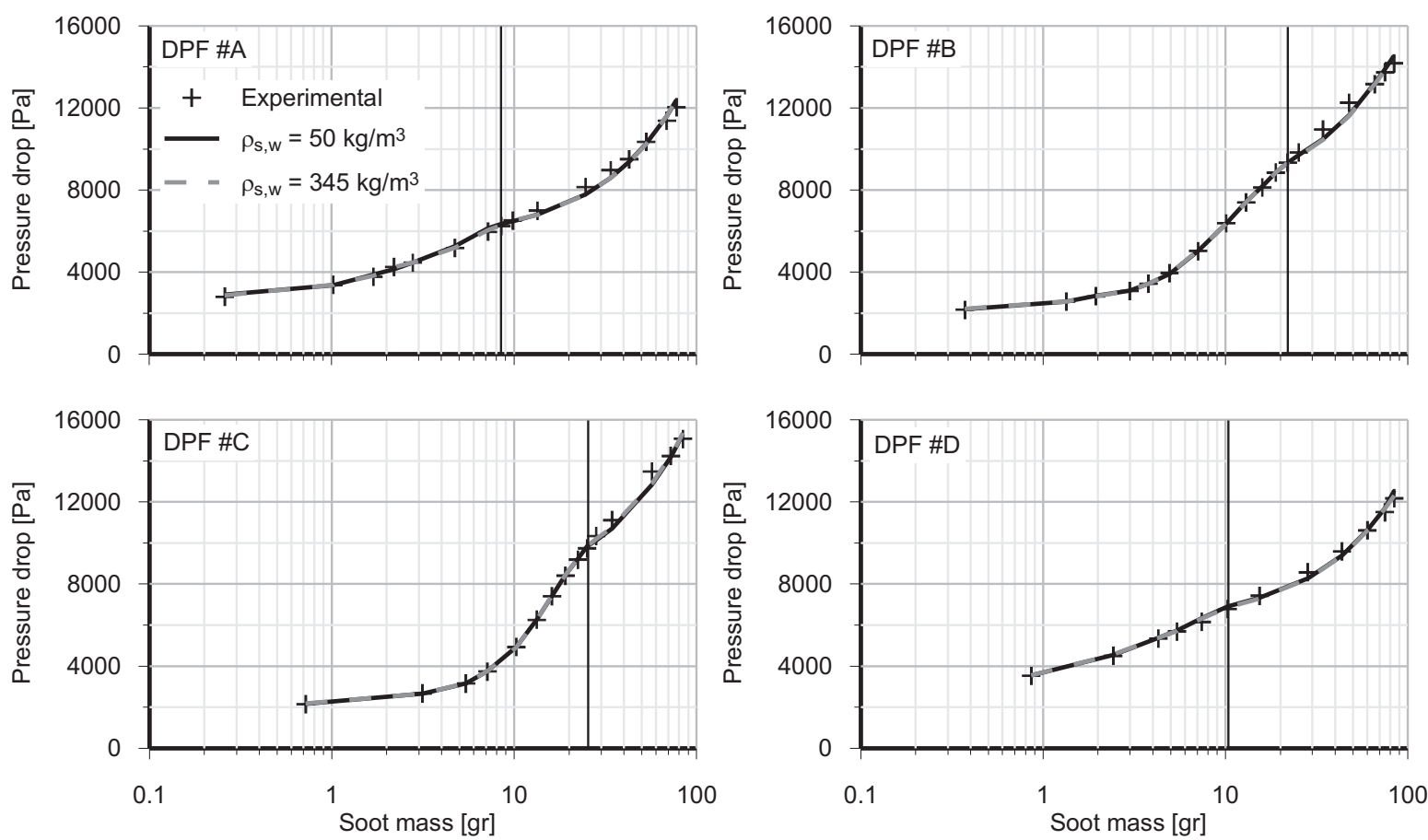

Figure 1: Modelling of pressure drop vs. soot mass for DPFs \#A, \#B, \#C and \#D assuming $\rho_{s, w}$ equal to $50 \mathrm{~kg} / \mathrm{m}^{3}$ and $345 \mathrm{~kg} / \mathrm{m}^{3}$.

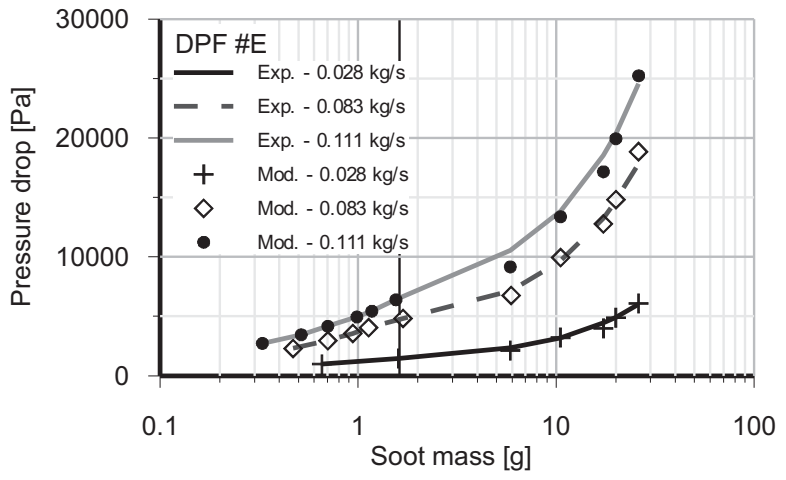

Figure 2: Modelling of pressure drop vs. soot mass for DPF \#E as function of the mass flow across the DPF at ambient conditions. 


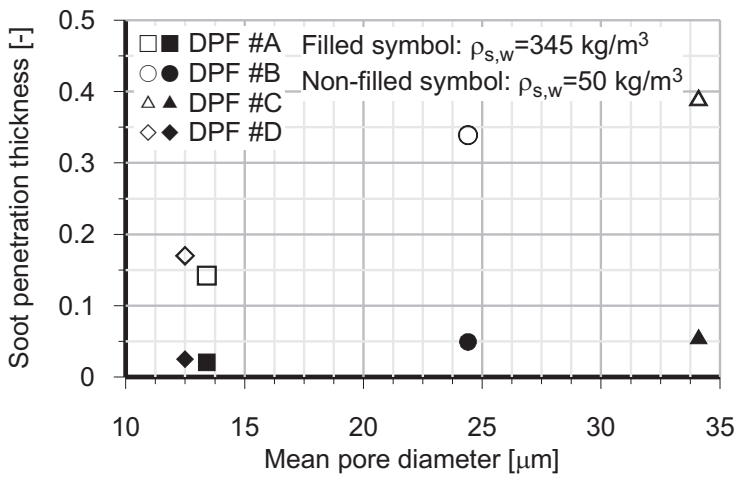

Figure 3: Fraction of porous wall with soot penetration for DPFs \#A, \#B, \#C and \#D assuming $\rho_{s, w}$ equal to $50 \mathrm{~kg} / \mathrm{m}^{3}$ and $345 \mathrm{~kg} / \mathrm{m}^{3}$.
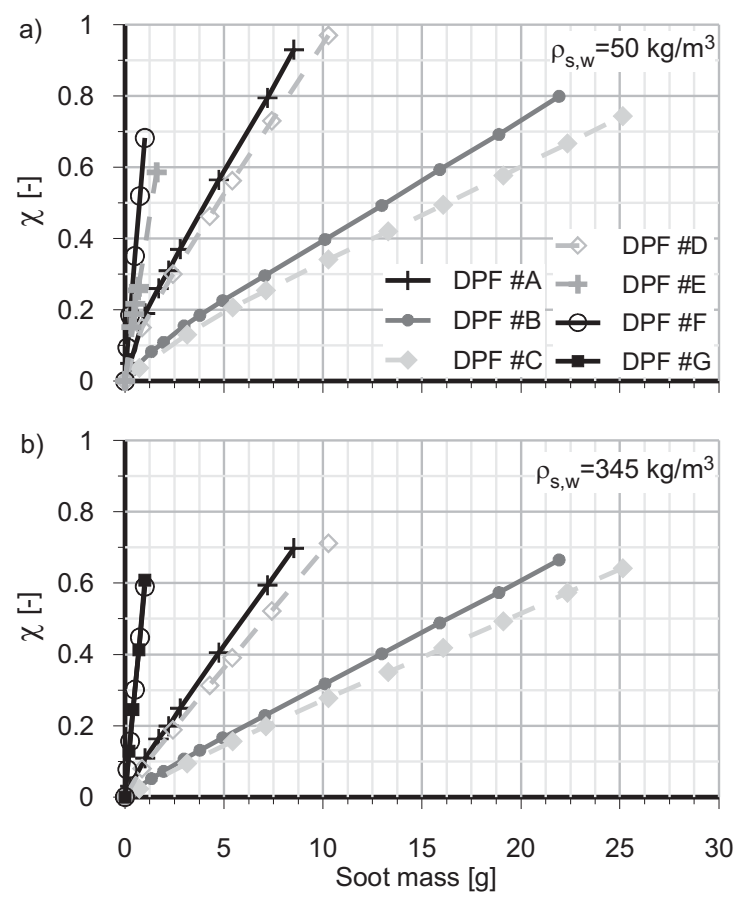

Figure 4: Shape factor as function of collected soot mass inside the porous wall for every DPF.

a)

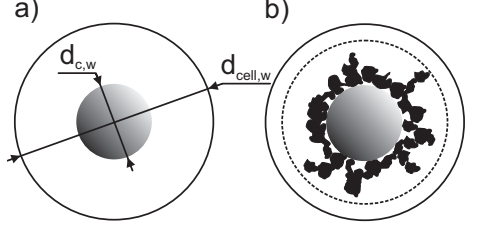

c)

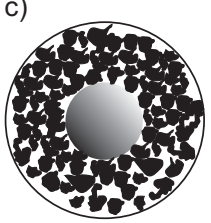

Figure 5: Sketch of collector diameter growth in a cell unit as the soot mass inside the porous wall increases. 

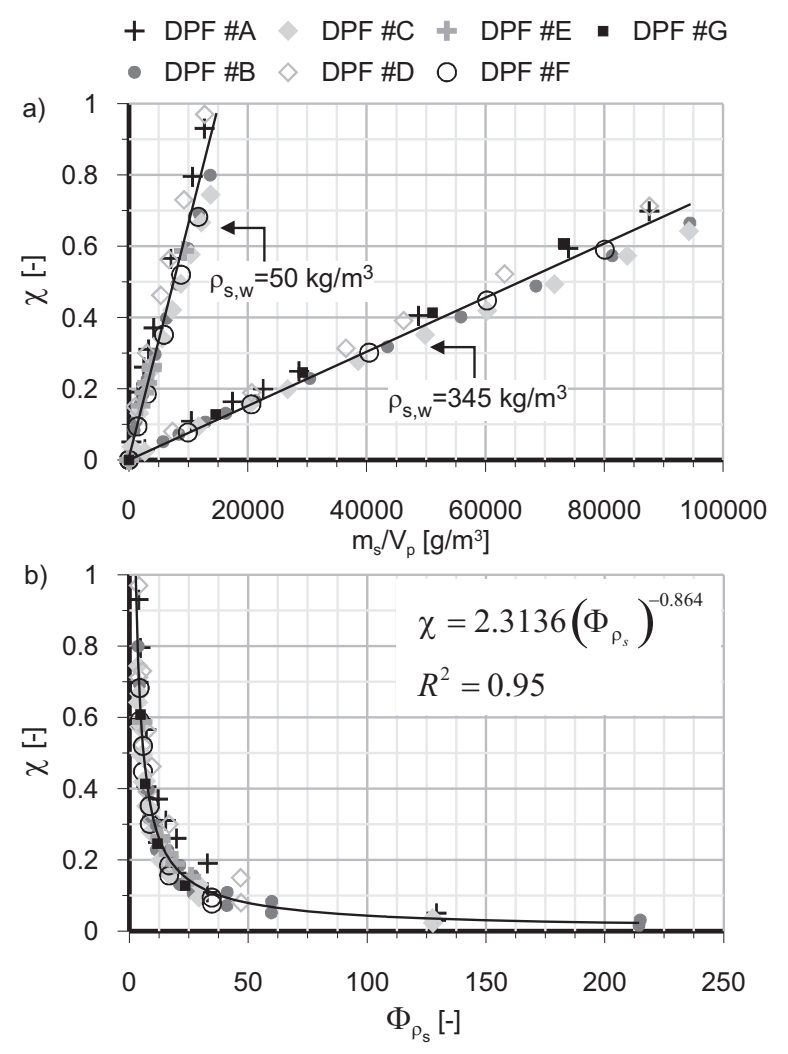

Figure 6: Shape factor correlation with soot density factor $\Phi_{\rho_{s}}$. 

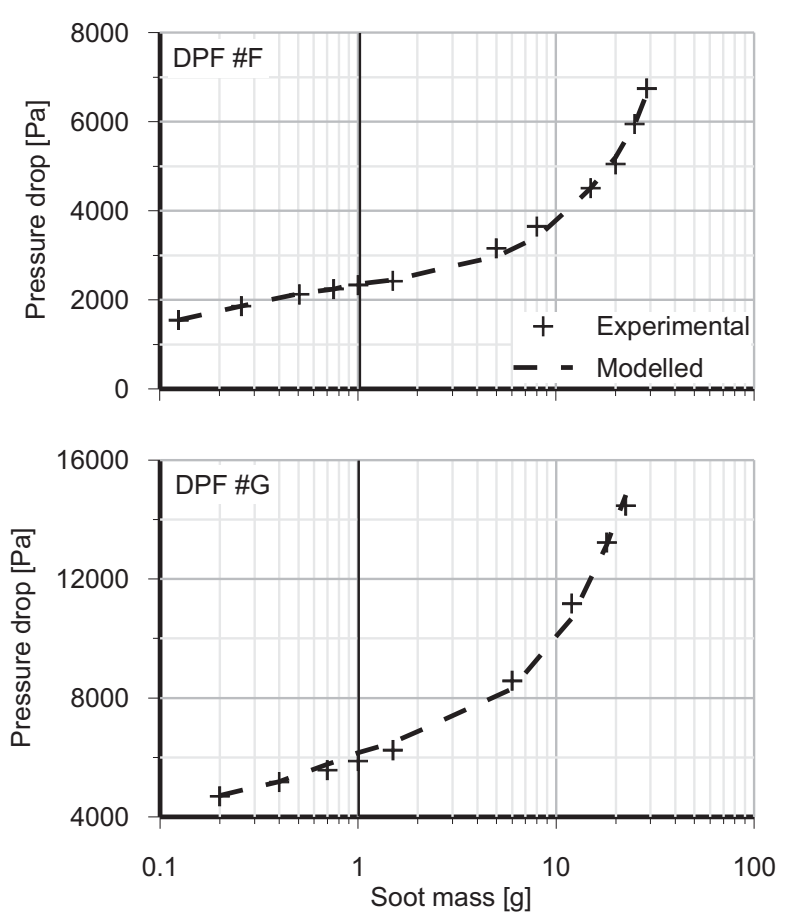

Figure 7: Modelling of pressure drop vs. soot mass for DPFs \#F and \#G.

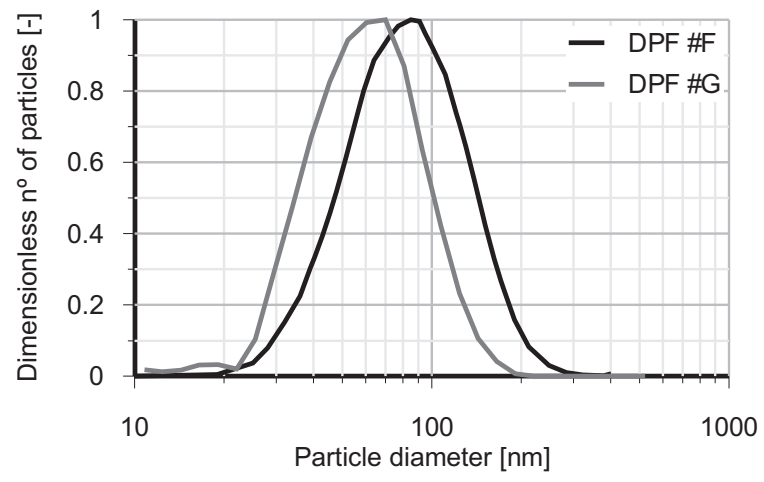

Figure 8: Particle size distribution emitted upstream of the DPFs \#F and \#G during the soot loading test. 


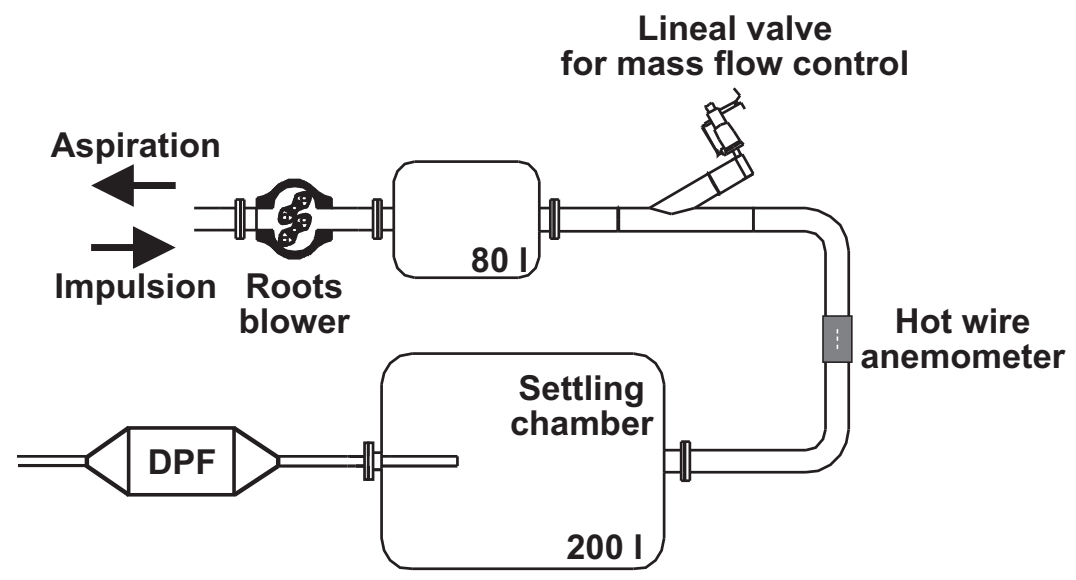

Figure 9: Scheme of the gas stand to characterise pressure drop in loaded DPFs \#F and \#G at room temperature as function of mass flow.

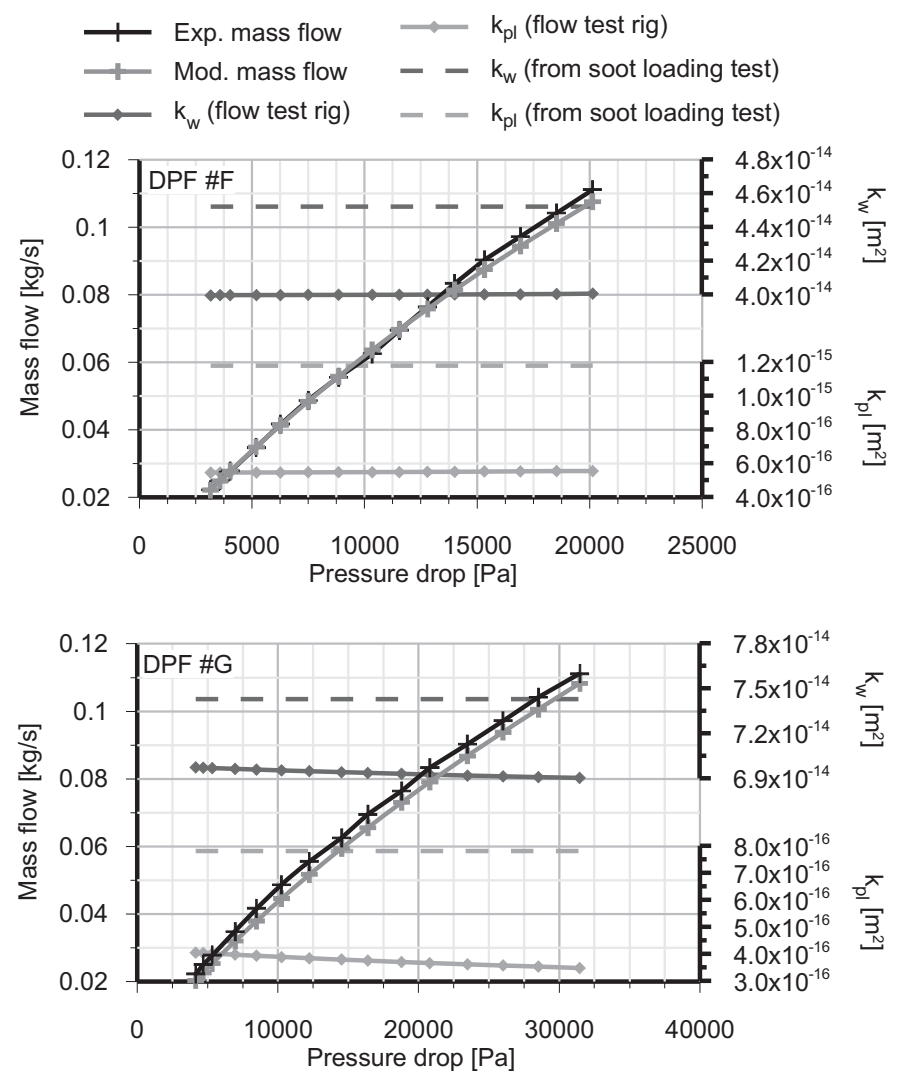

Figure 10: Mass flow prediction as function of pressure drop in gas stand at $20^{\circ} \mathrm{C}$ for DPFs \#F and \#G. Comparison between porous wall and particulate layer permeability in this test and the corresponding to the soot loading test. 